\title{
Ein Babykopf und sein Vater
}

\section{Iris Ritzmann}

Prof. Dr. med. et lic. phil., Mitglied der Redaktion Medizingeschichte

Was auf den ersten Blick an einen zersägten Babykopf erinnert, diente in Wirklichkeit als Modell in der Geburtshilfe. Engpässe im Geburtskanal wurden für einmal nicht am weiblichen Becken illustriert, sondern an den unterschiedlichen Ebenen des kindlichen Kopfes. Der Kinderkopf zeigt im Schnitt das Planum occipito-frontale, die Ebene zwischen Hinterkopf und Stirn sowie zwei Querdurchmesser. Das Modell gehört zu einer ganzen Reihe von Kopfformen, die in der Schule für Hebammenwesen der Charité Berlin in den 1920er Jahren mit zum Unterrichtsmaterial gehörte. Die Hebammenschülerinnen lernten unter ärztlicher Leitung die anatomischen Strukturen und physiologischen Abläufe der Geburt kennen. Noch bildete die Niederkunft in einer Gebäranstalt die Ausnahme, doch die Frauenärzte rührten bereits erfolgreich die Trommel gegen freischaffende Hebammen und Hausgeburten ohne ärztliche Leitung.

Modell eines Kinderkopfs nach Hugo Sellheim im Berliner Medizinhistorischen Museum der Charité, Dauerausstellung (wegen Umbau bis 2021 geschlossen).

Einer von ihnen war

Hugo Sellheim (1871-1936), Professor für Gynäkologie und Geburtshilfe in Berlin und Leipzig. Von ihm stammen die Vorlagen, nach denen die Kopfmodelle mit den verschiedenen Durchmesserflächen hergestellt wurden. Sellheims Spezialgebiet war die Geburtsmechanik. Nicht nur Hebammen, auch Ärzte, ja sogar interessierte Laien, folgten seinem Unterricht und lasen seine Lehrbücher. Mit einer grossen Zahl von Modellen und Übungsphantomen strebte er danach, seinen Studenten und Hebammenschülerinnen eine räumliche Vorstellung des Gebärvorgangs zu vermitteln. Sellheim stellte «die Gebärmutteraktion als hydraulische Presse, das Geburtsobjekt als Fruchtwalze» dar.

In den zwanziger Jahren von einigen Fachkollegen sehr kritisch aufgenommen wurde Sellheims Blick auf «das ganze Geheimnis naturgemässen Frauenlebens», den er in einem viel gelesenen Handbuch mit einem Satz zusammenfasste: "Jede Frau ist eine implizierte Mutter, und erst eine Mutter in ihrer Ehe und mit ihren Kindern ist eine explizierte Frau.» Seine Warnung vor weiblicher Berufstätigkeit, seine bevölkerungspolitischen

Abhandlungen und schliesslich auch gewagte Fruchtbarkeitsoperationen wie die Einpflanzung der Tuben in den Uterus rundeten dieses konservative Frauenbild ab. Im Nationalsozialismus galten Sellheims Ideen dagegen als fortschrittlich und weitblickend. Folgerichtig unterstützte der Mann, der den geburtshilflichen Kinderkopf schuf, die völkisch-nationale Politik nicht nur als Geburtshelfer, sondern auch als Mitglied mehrerer nationalsozialistischer Gruppierungen.

Bildnachweis

Iris Ritzmann, 2019 